\title{
Folclore, Linguagem e Interação: Perspectivas para uma Visão Transcultural da Cultura
}

\author{
Folklore, Language and interaction: Perspectives for a Cross-Cultural Vision of Culture
}

Folclore, lenguaje y interacción: perspectivas para una visión transcultural de la cultura

\author{
Joel Cezar Bonin ${ }^{1}$ \\ Fabiana Dalilla Becker ${ }^{2}$ \\ Rita Márcia Twardowski ${ }^{3}$ \\ Suéli Taiane Vicentim ${ }^{4}$ \\ Vânia Cristina Marcon da Rocha Lusa ${ }^{5}$
}

\section{Resumo}

A proposta deste artigo é estabelecer uma correlação entre folclore, interação e linguagem. $\mathrm{O}$ folclore como identidade social e cultural de um povo é abordado, num primeiro momento, desde a origem da palavra, passando pelo amparo legal que o fundamenta, ganhando notoriedade nesse campo de conhecimento em nosso país, buscando compreender algumas características do termo, como aceitação coletiva, difusa e de origem popular, herdado da junção do entroncamento dos povos indígenas, negros e europeus. Além disso, os estudos sobre o folclore ganharam novo fôlego com atualizações importantes em uma visão transversal. A segunda etapa do presente artigo apresentar a linguagem em uma combinação com a cultura e a relativa importância da maneira que ela se manifesta, principalmente na construção da escrita e preservação cultural. Busca entender o sentido da diversidade cultural, manifestada por meio da linguagem, como ponto de complementação e de interlocução e não como elemento de desagregação e disjunção. A última etapa do artigo é argumentação em torno da Weltanschauung, um conceito expressivo e abrangedor da realidade, que é uma maneira subjetiva ver e entender o mundo. Aquilo que se vê e se compreende precisa ser filtrado pela "visão de mundo". A necessidade de uma visão transcultural e transdisciplinar se faz necessária, já que o mundo que temos é resultado de nossa visão e interpretação do mundo vivido. Assim, na relação estabelecida entre linguagem, cultura e folclore, não se encontra um fechamento, uma unilateralidade de uma cultura, mas, sim, uma fusão que se enriquece

\footnotetext{
${ }^{1}$ Doutor em Filosofia pela PUC-PR. Professor do PPGEB - UNIARP, Caçador-SC. Email: joel@uniarp.edu.br. ORCID: https://orcid.org/0000-0003-0437-7609;

${ }^{2}$ Mestranda pelo PPGEB - UNIARP, Caçador-SC. Professora de Língua Inglesa na Escola de Educação Básica Expedicionário Mário Nardelli, em Rio do Oeste-SC. Email: fabianadalila35@ gmail.com ORCID: https://orcid.org/0000-0002-6267-5965

${ }^{3}$ Mestranda pelo PPGEB - UNIARP, Caçador-SC. Professora de Geografia na Escola de Educação Básica Professor Clementino Britto, de Porto União-SC, ritatwardowski@ yahoo.com.br. Orcid: https://orcid.org/0000$\underline{0003-4151-6743}$

${ }^{4}$ Mestranda pelo PPGEB - UNIARP, Caçador. Coordenadora de Patrimônio/Compra Rotativa da Secretaria Municipal de Educação-União da Vitória/PR. Email: suhtaiane@yahoo.com ORCID: https://orcid.org/00000002-8851-2005;

${ }^{5}$ Mestranda pelo PPGEB - UNIARP, Caçador-SC. Professora de Língua Inglesa na Escola Municipal de Educação Básica Pierina Santin Perett, em Caçador-SC. Email: lusavania060@gmail.com ORCID: https://orcid.org/0000-0003-2472-8330
} 
mutuamente. Essa relação assume relevância para uma abordagem transcultural, necessária para a construção identitária de uma sociedade.

Palavras-chave: Folclore; Linguagem; Transculturalidade; Weltanschauung.

\begin{abstract}
The purpose of this article was to establish a relationship between language, culture and folklore. Folklore, as a social and cultural expression of a folk, was discussed in the first step of the text, since the origin of the word, through the laws that ensure the freedom to experience it, until an overview in Brazil, trying to understand that we experience and feel the folklore in our daily lives, inherited from the junction of different folks. Besides that, the impact of folklore in a cross-sectional view was written. In the second step, we tried to show the language in its relation with culture and the importance of language, mainly written, in the construction and cultural preservation. We tried to understand the sense of cultural diversity expressed through the language, as a point of complementation and interlocution and not as an element of disaggregation and disjunction. The last stage of the article was the debate around Weltanschauung, a concept that embraces reality, which serves as a basis for the interpretation of the world. What is seen and understood, needs to be filtered by the "world view". The need of a cross-cultural and transdisciplinary vision is necessary, since the world we have is the result of ourselves and the interpretation of the lived world. So, in the relationship between language, culture and folklore, there is not a closure, a one-sidedness of a culture, but a fusion that enriches each other. This relationship assumes relevance for a transcultural approach, necessary for the construction of a society's identity.
\end{abstract}

Keywords: Folklore; Language; Transculturalism; Weltanschauung.

\title{
Resumen
}

La propuesta de este artículo es establecer una correlación entre Folclore, interacción y lenguaje. El folclore como identidad social y cultural de un pueblo es abordado en un primer momento, desde el origen de la palabra, pasando por el amparo legal que lo fundamenta, ganando notoriedad en ese campo de conocimiento en nuestro país, buscando comprender algunas características del termo, como aceptación coletiva, difusa y de origen popular, heredado de la junción del entroncamiento de los pueblos indígenas, negros y europeos. Además, los estudios sobre el folclore ganaron nuevo aliento con actualizaciones importantes em una visión transversal. La segunda etapa del presente artículo presenta el lenguaje en una combinación con la cultura y la relativa importancia de la manera que ella se manifiesta, principalmente en la construcción de la escrita y preservación cultural. Busca comprender el sentido de la diversidad cultural, manifestada a través del lenguaje, como punto de complementación y de interlocución y no como elemento de desagregación y disyunción. La última etapa del artículo es argumentación sobre la Weltanschauung, concepto expresivo y que abarca la realidad, que es una manera subjetiva ver y comprender el mundo. Aquello que se ve y se comprende, necesita ser filtrado por la "visión de mundo". La necesidad de una visión transcultural y transdisciplinar se hace necesaria, pues el mundo que tenemos es resultado de nuestra visión e interpretación del mundo vivido. Así, en la relación establecida entre lenguaje, cultura y folclore, no se encuentra un cierre, una unilateralidad de una cultura, 
pero, sí, una fusión que se enriquece mutuamente. Esta relación adquiere relevancia para un enfoque transcultural, necesario para la construcción de la identidad de una sociedad.

Palabras clave: Folclore; Lenguaje; Transculturalidad; Weltanschauung.

\section{Introdução}

Falar sobre cultura parece ser uma prática recorrente se abordada por uma perspectiva unidimensional. Todavia, pensar a cultura a partir de um olhar multifacetado pode nos levar para uma compreensão mais ampla e profunda dos fenômenos culturais, haja vista a compreensão comumente aceita e difundida por Edward Tylor sobre cultura. Outrossim, a definição do antropólogo inglês é aceita como a forma mais complexa e abrangente de definição do vocábulo cultura. Em suas palavras, cultura é "aquele todo complexo que inclui o conhecimento, as crenças, a arte, a moral, o direito, os costumes, e qualquer outro hábito e capacidade adquirida do homem" (TYLOR, 1871, p.31). Por esse entendimento, podemos compreender que falar sobre cultura implica falar sobre vários aspectos que, recorrentemente, podem passar despercebidos pela maioria das pessoas.

Desse modo, o artigo proposto busca abordar alguns elementos fundamentais da noção de cultura, de modo especial, as manifestações folclóricas e linguísticas. Falar sobre folclore não é apenas expressar uma forma de análise daquilo que se manifesta no cotidiano das pessoas, mas também compreender que existem formas de interpretação de suas irrupções. Assim, tenta-se mostrar como o folclore surge como sincretismo do encontro de muitas interpretações de mundo e de muitas formas de linguagem popular.

Concomitantemente a isso, destaca-se em nosso texto a importância, a partir da noção de sincretismo, da transculturalidade e da linguagem. As palavras tentam expressar as coisas, porém, essas coisas podem ser abstratas e só podem ser assimiladas dentro do universo cultural no qual as pessoas estão inseridas. Assim, a abstração não é intangível, mas é, ao contrário, expressão da visão de mundo cultural de uma localidade, de um estado ou país. Assim sendo, a territorialidade pode ser um elemento importante para compreender uma cultura. Contudo, as bordas limítrofes de cada cultura não se limitam ao espaço geográfico, pois ultrapassar as suas fronteiras é uma das características mais comuns de todas as culturas presentes no mundo.

Assim sendo, nosso texto se divide nas seguintes etapas: a) o folclore como manifestação cultural e social de um povo; b) a necessidade de uma visão transcultural da 
cultura; c) a Weltanschauung e a importância da linguagem para a constituição das identidades pessoais e d) considerações finais.

\section{O Folclore como manifestação cultural e social de um povo}

Falar sobre folclore é falar de todas as manifestações culturais populares de um povo. Para tanto, a Organização das Nações Unidas para Educação, Ciência e Cultura (UNESCO) considera o Folclore como Patrimônio Cultural Imaterial, enfatizando que sua preservação é de extrema importância. Da ideia de imaterialidade, surge a compreensão da intangibilidade como um elemento importante para a assimilação do conceito de abstração. Os elementos folclóricos de um povo podem ser pontuados (não só, mas principalmente) a partir de narrativas, contações de histórias/estórias, lendas e parlendas. Desse modo, pensar o folclore implica pensar no processo comunicativo de repasse dessas informações. Nesse sentido, a abstração e a intangibilidade são fatores importantes para a compreensão dos aspectos folclóricos de um povo.

Não obstante, a origem da palavra "folclore" ocorreu em 22 de agosto de 1846, através do arqueólogo inglês Willian John Thoms, que empregou, “[...] a palavra folk-lore, composta de dois vocábulos saxônicos antigos: folk, significando povo, e lore, que quer dizer conhecimento ou ciência" (MEGALE, 2011, p. 11). Palavra essa, que sofreu aportuguesamento e atualmente é muito conhecida e utilizada em nosso país como folclore, pois ainda, segundo Megale:

No Brasil, após a reforma ortográfica de 1934, que eliminou a letra K, a palavra perdeu também o hífen e tornou-se folclore. O folclore é encontrado na literatura sob a forma de poemas, lendas, contos, provérbios e canções, assim como nos costumes tradicionais como danças, jogos, crendices e superstições. Verifica-se também sua existência nas artes e nas mais diversas manifestações da atividade humana. (MEGALE, 2011, p.11-12).

Dessa forma, o folclore se apresenta no simbolismo, na identidade cultural e nas tradições de cada povo, das mais variadas formas e nas diversas faces das classes sociais, se perpetuando na história através das gerações e influenciando na nossa maneira de viver.

Em 1995, fora realizado em Salvador-BA o "VIII Congresso Brasileiro de Folclore" organizado pela Comissão Nacional de Folclore, o qual fez uma revisão da Carta do Folclore 
Brasileiro que foi elaborada no "I Congresso Brasileiro de Folclore" realizado em 1951 no Rio de Janeiro-RJ. Tal revisão se fez necessária para a atualização de estudo e proteção do folclore brasileiro frente aos avanços das ciências sociais e humanas, considerando recomendações emitidas pela UNESCO, definindo em seu capítulo I que:

Folclore é o conjunto das criações culturais de uma comunidade, baseado nas suas tradições expressas individual ou coletivamente, representativo de sua identidade social. Constituem-se fatores de identificação da manifestação folclórica: aceitação coletiva, tradicionalidade, dinamicidade, funcionalidade. Ressaltamos que entendemos folclore e cultura popular como equivalentes, em sintonia com o que preconiza a Unesco. A expressão cultura popular manter-se-á no singular, embora entendendo-se que existem tantas culturas quantos sejam os grupos que as produzem em contextos naturais e econômicos específicos. (CARTA DO FOLCLORE BRASILEIRO, 1995 [s.n.]).

Como vimos, em nossa introdução, Tylor expõe que cultura é um complexo de fatores que se conjugam, que se reúnem e que formam uma amalgama coesa. Com esse pressuposto em mente, nota-se que a Carta do Folclore Brasileiro coaduna perfeitamente com a ideia apresentada por Tylor, pois os fatores de identificação folclórica não são somente elementos que estão dispersos e difusos na realidade social de uma comunidade ou povo, mas estão sincretizados e amalgamados, de modo que não se vê uma separação entre os fatores, mas uma conjugação constante entre eles. A noção de complexo dada por Tylor dá a entender de que falar sobre cultura (e, consequentemente, em folclore) resulta na ideia de que compreender a vida social de um povo é corolário não apenas da soma das partes que a compõe, mas de uma visão ampla e pormenorizada do todo.

Dessa forma, no Brasil, o Dia do Folclore foi oficializado em 17 de agosto de 1965 por meio do Decreto $\mathrm{n}^{\circ}$ 56.747, assinado pelo então presidente militar Humberto de Alencar Castello Branco e por seu Ministro da Educação, Flávio Suplicy de Lacerda, conforme seus três artigos:

Art. $1^{\circ}$ Será celebrado anualmente, a 22 de agosto, em todo o território nacional, o Dia do Folclore.

Art. $2^{\circ}$ A Campanha de Defesa do Folclore Brasileiro do Ministério da Educação e Cultura e a Comissão Nacional do Folclore do Instituto Brasileiro da Educação, Ciência e Cultura e respectivas entidades estaduais deverão comemorar o Dia do Folclore e associarem-se a promoções de iniciativa oficial ou privada, estimulando ainda, nos estabelecimentos de curso primário, médio e superior, as celebrações que realcem a importância do folclore na formação cultural do país.

Art. $3^{\circ}$ Revogam-se as disposições em contrário. (BRASIL, Dec. 56.747/65). 
Atualmente, o direito do indivíduo em vivenciar as diversas formas de manifestação cultural é garantido nos artigos 215 e 216 da Constituição da República Federativa do Brasil de 1988:

Art. 215. O Estado garantirá a todos o pleno exercício dos direitos culturais e acesso às fontes da cultura nacional, e apoiará e incentivará a valorização e a difusão das manifestações culturais.

Art. 216. Constituem patrimônio cultural brasileiro os bens de natureza material e imaterial, tomados individualmente ou em conjunto, portadores de referência à identidade, à ação, à memória dos diferentes grupos formadores da sociedade brasileira nos quais se incluem:

I - As formas de expressão;

II - Os modos de criar, fazer e viver;

III - As criações científicas, artísticas e tecnológicas;

IV - As obras, objetos, documentos, edificações e demais espaços destinados às manifestações artístico-culturais;

V - Os conjuntos urbanos e sítios de valor histórico, paisagístico, artístico, arqueológico, paleontológico, ecológico e científico.

Por esse prisma e com base nessas questões legais, culturais e sociológicas, é preciso ponderar sobre o impacto do folclore em uma visão transversal, pois somente a cultura isolada de sua fundamentação legal pode ser incompleta. Sabemos que o folclore tem grande influência sobre a cultura popular brasileira, haja vista que suas contribuições visam manter a oralidade cultural e literária presente em toda sociedade. De outro lado, deve-se lembrar que a mídia massificada e fortemente influenciada pelo viés não-literário coaduna com os pressupostos da produção industrializada que tentam uniformizar o que se entende por cultura. Na percepção da identidade cultural, não é raro ouvirmos afirmações de que valores e referenciais identitários estão sendo aniquilados. Nesse intento, busca-se compreender o que restringiu esses estudos culturais dentro dos processos de conhecimento e reconhecimento das pessoas.

Portanto, resgatar a identidade cultural demanda a necessária compreensão de que todos nós vivenciamos e sentimos o folclore no nosso cotidiano, herdado da junção dos diferentes povos e que se apresenta nas superstições, nos ditados populares, crendices, ervas medicinais, cantos, festas, parlendas, trava-línguas, entre outros e, segundo Megale (2011, p. 24): “As origens do folclore brasileiro prendem-se à formação do seu povo. Três elementos básicos - o índio, o branco e o negro - aqui se misturaram, fundindo numa só as diferentes culturas".

Embora algumas das manifestações não sejam criações espontâneas do folclore brasileiro, a circulação dos "fatos sociais" é uma realidade inegável. Dessa forma, a contação 
de várias estórias e histórias, recebe características regionalizadas que transformam os fatos em mitos e crendices. Nesse contexto, foram incorporadas e criadas as tradições do nosso país. Sobre isso, deve-se salientar que a originalidade de cada relato folclórico pontual não é apenas uma maneira de manter viva a narrativa de histórias/estórias, mas cultura viva das identidades regionais.

Desse intricado mosaico composto pelas etnias indígenas, pelo português e pelos africanos com diferentes níveis de cultura, Alfredo João Rabaçal discorre:

O folclore brasileiro é basicamente, o produto do encontro dessas três correntes. É o produto da aglutinação, num efervescente caldeamento reinterpretativo, de traços e complexos dessas culturas, originando não só manifestações especificamente nacionais, como também regionais e locais. (RABAÇAL, 1967, p. 3)

Em relação à cultura indígena, herdamos os mistérios da natureza em que o respeito pelas águas, terras e animais se faz muito presente em suas tradições; as fábulas e contos trazem como heróis os animais de nossas matas como o Boitatá, Iara, Saci-Pererê etc. Lendas como a origem do guaraná, da mandioca; as danças e um forte artesanato com matéria-prima extraída da natureza como madeira, argila, palha, plumagem e o hábito de banhos frequentes são manifestações de origem indígena. As contribuições da cultura europeia em nosso folclore trazem referência na literatura como Pedro Malasartes, Chapeuzinho Vermelho, fadas e madrastas. É fortemente encontrada a tradição europeia nas questões de cunho religioso de devoção, nas festas juninas, natalinas e no famoso carnaval. A presença portuguesa pode ser vista igualmente no artesanato por meio das rendas, bordados e pinturas.

Por sua vez, crenças religiosas e rituais como o Candomblé, Umbanda e Macumba, bem como, divindades como Iemanjá, Ogum, Oxalá são manifestações culturais de origem africana que foram incorporadas a nossa cultura pelos afrodescendentes. Estes também foram responsáveis por nos apresentar o samba, a capoeira e algumas especiarias gastronômicas como o vatapá, o acarajé, a cocada, o quindim, dentre outras. (MEGALE, 2011).

Assim sendo, o folclore destaca-se entre a linguagem oral e escrita, tendo a literatura, costumes e crenças como principais manifestações artísticas que são transmitidas através da comunicação entre os povos. Entre as principais formas de transmissão, podem-se destacar os gestos, os registros e a oralidade. Nesse ponto, deve-se salientar o uso da linguagem informal 


\section{ODEVIR EDUCAÇÃO \\ ISSN: 2526-849X}

entre o falar e o ouvir, comumente expressa como linguagem coloquial, isenta de normas gramaticais, de acordo com as formas de comunicação necessárias para o convívio social.

Tendo essa constatação em mente, é fulcral destacar que a linguagem é um dos elementos mais marcantes para se compreender as dimensões folclóricas de uma cultura ou povo. A ideia de transformar pensamentos em palavras e tornar isso inteligível por meio da comunicação é um dos aspectos mais fascinantes da interação humana. A linguagem falada e escrita representa um dos fatores essenciais da diversidade humana e um dos quesitos fundamentais para o reconhecimento do valor da interatividade transcultural.

Dessa breve conclusão, deseja-se agora abordar a visão transcultural da cultura por meio da linguagem de modo mais pormenorizado, de tal maneira que nos convêm abordar nosso próximo item, elencando os diversos pontos de amarração que costuram o folclore com a linguagem e a comunicação.

\section{A necessidade de uma visão transcultural da cultura}

Uma vez que é a linguagem, na sua relação dialógica, que constrói e perpetua a cultura, pois esta tem seu papel emancipatório e auxiliar na constituição de sujeitos críticos, capazes de interferir, transformar ou manter o espaço em que vivem sem perder as características regionais, é preciso destacar a relação entre linguagem e cultura de modo claro e enfático.

Em outras palavras, os elementos que transformam os sujeitos pertencentes a uma comunidade em sujeitos singulares podem ser condensados em dois termos: cultura e linguagem. Portanto, faz-se necessário destacar algumas ideias que tratam da relação entre as diferentes culturas e as diversas formas de linguagem existentes nestas culturas, seja de modo intra ou extracultural.

Nesse sentido, há três conceitos fundamentais: universalismo, relativismo e multiculturalismo. Pereira e Silva (2013 apud BARROSO; BONETE, QUEIROZ, 2017) ressaltam que o universalismo reconheceu a dignidade humana, desconsiderando as diferenças culturais. Para tanto, eles se basearam na Declaração Universal dos Direitos do Homem, que foi o documento adotado pelas Nações Unidas (ONU) para defender a dignidade da pessoa humana. Assim: 
Com a universalização, portanto, buscou-se proteger o indivíduo simplesmente por ser um ser humano, independente de seu país, de sua cultura. Apenas a condição de ser humano é que interessa ao universalismo cultural, já que tais direitos decorrem inescapavelmente da própria dignidade humana, entendida como valor indissociável da condição de ser humano (PEREIRA, SILVA, 2013 apud BARROSO, BONETE, QUEIROZ, 2017, p. $50)$.

Todavia, os mesmos autores destacam que é imprescindível que se tenha um certo cuidado ao utilizar esse conceito, pois no contexto do imperialismo e da globalização, esse argumento pode ser utilizado para interferir nas culturas locais diversas, visando à dominação e a aculturação dos povos (BARROSO; BONETE, QUEIROZ, 2017).

Já o relativismo defende a preservação das diferenças culturais e a preservação das identidades e diversidades das inúmeras sociedades existentes, respeitando a autonomia de cada nação, de cada povo, numa relação de respeito aos valores e crenças de cada sociedade (BARROSO; BONETE, QUEIROZ, 2017).

Ainda de acordo com Barroso, Bonete e Queiroz (2017), no multiculturalismo deve haver harmonia na convivência da pluralidade cultural pois, nesse sentido, defende-se uma ideia aglutinadora, híbrida e agregadora de direitos humanos que consideram tanto as igualdades quanto as diferenças entre as pessoas. Nesse sentido, Silva e Pereira afirmam:

O multiculturalismo, tal como eu entendo, é pré-condição de uma relação equilibrada e mutuamente potenciadora entre a competência global e a legitimidade local, que constituem os dois atributos de uma política contrahegemônica de direitos humanos no nosso tempo (PEREIRA, SILVA, 2013 apud BARROSO; BONETE, QUEIROZ, 2017, p. 51).

Assim sendo, vemos que falar sobre ideias multiculturais resulta por corolário na necessidade de se pensar em formas "não-oficiais" de pensamento cultural. De um modo geral, pensar uma visão unívoca sobre cultura é um grave erro pois em nenhuma localidade, as manifestações culturais expressam a totalidade identitária de um povo. Existe sempre uma visão do todo quando se pensa em manifestações culturais, mas elas não representam por completo o modo de ser de uma localidade. Podemos pensar que, em determinadas regiões do Estado de Santa Catarina, por exemplo, as manifestações culturais de matriz germânica sejam predominantes, mas nem todos os habitantes destas regiões são de descendência germânica. Assim, manifestações culturais de outra nacionalidade (ou propriamente brasileiras) são formas contra hegemônicas para demonstrar a importância do multiculturalismo em 
detrimento do culturalismo, pois onde há hegemonia cultural, sempre podem ser encontradas formas de manifestação contra hegemônica.

Dessa forma, retomando a ideia de criticidade adquirida pela linguagem, temos na literatura (que não se expressa somente em livros "oficiais") um forte aliado no desenvolvimento do pensamento crítico, como forma de combate ao controle ideológico estabelecido pela classe dominante, pois

A Literatura é uma dessas disciplinas que, com o seu potencial dialético, possibilita leituras de mundo das mais variadas que pode ou não culminar em análises que questionam a estrutura social e econômica e sistemas de exploração de grupos sociais sobre outros (OLIVEIRA, 2016, p. 42).

Dessa forma, a partir da necessidade que a humanidade teve de viver em comunidades, surgiu um importante meio de produção e perpetuação cultural, que é a linguagem. Segundo Busatto (2003 apud BRANDT; GUSTSACK; FELDMANN, 2009, p.174), "a literatura oral é a mais genuína das expressões culturais da humanidade, não sendo possível lhe atribuir uma paternidade". Se compararmos a literatura oral com a literatura escrita, observamos na primeira algumas características que dão a ela uma estrutura única. A pronúncia, o ritmo, o estilo e a seleção das palavras estão a serviço da memorização e contribuem para atrair a atenção do interlocutor. Segundo Bonvini, "os textos orais [...] convidam a partilhar com o outro a procura do sentido (BONVINI, 2016, p. 7). Os contadores de histórias foram, durante muito tempo, responsáveis pela perpetuação de mitos, fábulas e muitas outras formas de expressão oral. Já no texto escrito "a palavra se separa da pessoa, o passado é separado do presente e a relação com o outro e com seu universo espaço-temporal é mediatizada (BONVINI, 2016, p. 8).

Contudo, foi a linguagem escrita que possibilitou à humanidade a produção e apropriação da cultura e do conhecimento historicamente acumulado. Assim, ela se constitui como elemento fundamental na construção e preservação cultural, pois é através dela que as histórias são perpetuadas. À luz desse pensamento, há que se encontrar formas dinâmicas e eficientes para o desenvolvimento da competência linguística nos indivíduos, pois é através do seu uso que nos conhecemos, expomos nossas memórias e participamos do processo de constituição da língua que sendo viva, criativa e dinâmica, é constantemente modificada por seus falantes. 
Nesse viés, Bakhtin em seus estudos linguísticos, afirma que a língua é constituída nas relações dialógicas, a partir do pensamento e da troca com o outro, mediada pelo diálogo em um processo de interação constante, ou seja, a troca que acontece através da interação verbal permite a aquisição do conhecimento pelos sujeitos envolvidos nesse processo (LORENZETTI; CAMPOS, 2013). Assim, a dimensão dialógica se estende para além da troca de mensagens, mas como uma questão constitutiva das interações sociais.

De acordo com Geraldi (2013), Bakhtin apresenta uma crítica ao conhecimento instrumental, produzido para atender interesses privados ou políticos de grupos específicos, ao mesmo tempo em que afirma a importância do compromisso ético de cada um com a vida. Nessa perspectiva, a linguagem é responsável por expressar e traduzir os sentidos da experiência vivida, ou seja, "A ênfase está no lugar ocupado pelo olhar e pela palavra na constituição do sentido que conferimos à nossa experiência de estar no mundo, sentido esse atravessado por valores que fazem parte da cultura de uma época" (GERALDI, 2013, p.16)

Geraldi (2013) afirma ainda que para Bakhtin, em todo texto (e contexto de mundo) há o comparecimento do outro com suas contrapalavras que, pelo movimento de compreensão responsável dá vida à escuta e à escrita, construindo sentidos que são diferentes daqueles emitidos pelo locutor, ou seja, é a apropriação da linguagem, através da experiência dialógica, estabelecida nas relações sociais que propicia a comunicação e a inserção do sujeito no mundo, através da qual os indivíduos incorporam a mentalidade e a cultura da época em que vivem, transformando-a na medida que constroem significados diferentes daqueles já estabelecidos.

Corroborando com isso, Habermas (2012) defende que é fundamental que o desenvolvimento da linguagem aconteça de forma competente, pois para o autor, tal competência é imprescindível na formação de indivíduos emancipados que, pelo uso adequado da razão (construída pela competência linguística), desenvolvem capacidade argumentativa e que tal capacidade, sendo utilizada pela coletividade, induz os grupos sociais a discutirem seus dilemas e através do consenso, encontrarem formas de resolvê-los. Em outras palavras: para Habermas, é a competência linguística que facilita o entendimento entre os indivíduos, propiciando novas concepções culturais, induzindo às transformações sociais necessárias para a construção de uma sociedade mais justa (GOMES, 2007).

Desse modo, se considerarmos o início da linguagem até os dias atuais, observamos uma modificação, uma atualização constante das formas linguísticas. Como exemplo, 


\section{OO DEVIR EDUCAÇÃO}

ISSN: 2526-849X

destacamos que a criação lexical pode nascer meramente da intenção literária do autor de se expressar, mas também de uma necessidade de se expressar de maneira única (PINHEIRO, 2008, p. 17): "uma vez verificada a possibilidade da renovação do léxico e a propriedade do escritor em reconstruí-lo, torna-se nítido que as novas lexias foram criadas com uma intenção". Porém, para isso o escritor se utiliza de instrumentos que a própria língua oferece, dando ao texto seu estilo individual, sua interpretação e sua intenção.

Voltando ao conceito de Habermas sobre a competência linguística, que pode facilitar o entendimento entre indivíduos e entre concepções culturais, podemos entender a competência transcultural como fundamental. Segundo Heloísa Bacchi Zanchetta, esta

pode ser entendida como um estado de consciência em que o [sujeito] é capaz de refletir sobre o mundo e sobre si mesmo através das lentes de outra língua e outra cultura, sem julgamento do que é certo ou errado, do que é bom ou ruim. É compreender o outro, junto com suas crenças, história e ideologia, sem menosprezar sua cultura e reconhecê-lo como parte de um contexto sociocultural, bem como transformar-se a si mesmo e a sua própria formação cultural, no sentido de entender sua participação na sociedade (ZANCHETTA, 2015, p. 35).

Assim sendo, a formação e a identidade de cada pessoa demandam a presença da diferença. O diferente, seja do ponto de vista cultural ou linguístico, não devem despertar ojeriza ou repulsa, mas admiração e interesse. A diversidade cultural em nosso contexto de mundo deveria nos colocar em uma posição de aprendizado constante e não de afastamento. As diferenças culturais devem nos enriquecer a ponto de vermos os pontos de complementação e de interlocução e não os elementos de desagregação e disjunção. Assim, a capacidade de ver o outro "como um outro eu" é um desafio cultural, pois até mesmo do ponto de vista da formação cultural e identitária a partir "de nossas casas", fomos ensinados de que existe o "nós" e o "eles". Comumente, este "eles" foi nos apresentado como adversário, inimigo, inferior ou digno de exclusão.

Essa forma de excluir o outro, normalmente, foi dada sem maiores explicações ou demonstrações. Bastava que o outro fosse determinado como pertencente ao grupo do "eles". Tal determinação já era, por si só, motivo suficiente para a rotulação e o banimento. Desse modo, pensar a diversidade cultural torna-se uma necessidade premente de inclusão e aceitação de que o aprendizado de outras culturas não é uma tarefa piegas ou de soberba, mas uma questão de sobrevivência de nossas próprias identidades culturais, pois quanto mais 
aprendemos sobre outras realidades culturais e linguísticas, mais nos damos conta da intersecção e dos interstícios que coligam os valores sociais e culturais dos povos. Por isso, a emergência da transculturalidade e do diálogo intercultural.

Diante disso, convêm apresentar o ponto $c$ de nosso texto, a saber: a Weltanschauung e a importância da linguagem para a constituição das identidades pessoais.

\section{A Weltanschauung e a importância da linguagem para a constituição das identidades pessoais}

A ideia de Weltanschauung pode ser condensada em uma definição como cosmovisão ou, de modo mais genérico, como visão de mundo. A palavra é usada no seu termo em alemão, como união dos termos Welt (mundo) e Anschauung (visão). Essa ideia remete, segundo Fabio Ciraci (2019), à uma forma de compreensão que tenta abarcar todo saber e conhecimento que uma pessoa possui sobre o mundo. Assim sendo, a Weltanschauung se transforma em uma chave de leitura do mundo, um conceito abrangente e abrangedor da realidade, que serve de base para a interpretação do mundo. Aquilo que se vê e se compreende, precisa ser filtrado pela "visão de mundo" que as pessoas possuem. Essa visão, outrossim, é uma construção social dada pela cultura na qual os sujeitos estão postos.

Todavia, há perigos que devem ser evitados na medida em que a Weltanschauung assume uma visão unívoca e restrita do mundo. Assim, Ciraci adverte que

a Weltanschauung seria desse modo uma visão "abrangente" para dizê-lo com Karl Jaspers, que há lugar "[...] em um momento em que nosso mundo, nossa realidade, nossos objetivos são fixos e se tornam óbvios, ou ainda não experimentamos a possibilidade da visão do mundo ou ficamos rígidos em uma concha e não fazemos mais nenhuma experiência" (CIRACI, 2019, p. 268).

Dessa interpretação fixa e estanque da realidade, é possível compreender que a visão de mundo dos sujeitos no mundo é consequência na imersão de cada um em mundos existentes e possíveis, permeados e encharcados por elementos culturais locais ou nacionais. Sob esta égide, impera a força da linguagem e da comunicação que costura toda amalgama social. Contudo, como tentamos abordar em nosso texto, a lógica do isolamento e do 
solipsismo linguístico não aporta novidades ou transformações para a abertura à transculturalidade.

Assim sendo, pensar na Weltanschauung implica pensar em um ponto de partida e não de chegada. Em outras palavras: a visão de mundo que temos dá início à nossa existência como sujeitos culturais, capazes de enxergar e interpretar o mundo que nos cerca. Mas, para vermos para além dos muros e das cercas, é preciso convir que não é possível nos enredarmos em nossa própria realidade. É preciso galgar certos degraus que nos possibilitem ver o que está para além das fronteiras de nossa cultura. A necessidade de uma visão transcultural e transdisciplinar se faz necessária, já que o mundo que temos é resultado de nossa visão e interpretação do mundo vivido.

A Antropologia e a Filosofia sempre se preocuparam com a linguagem e com as formas possíveis de comunicação que os seres humanos inventaram para estabelecer pontes entre si. Essas pontes são criadas a partir da necessidade local ou nacional de interação entre os indivíduos que precisam se entender sobre o mundo e sobre as coisas no mundo, ou seja, localmente, a linguagem e/ou o idioma são resultado de "uma visão de mundo" que seja capaz de agregar os sujeitos sobre coisas comuns a todos, desde objetos até sentimentos.

Todavia, na medida em que os sujeitos são capazes de se entenderem localmente, criam-se grupos linguísticos, dentro desta mesma realidade, que expressam de modo diverso o seu entendimento sobre o mundo. Dessa constatação, vemos que criam-se igualmente, na medida do distanciamento territorial, novas formas de expressão e comunicação sobre as coisas no mundo. Desse simples entendimento, temos a simultaneidade da invenção de muitas visões de mundo diversas e heterogêneas; donde temos, por efeito, a ideia de diversidade cultural. Porém, essa verdade que nos parece autoevidente sempre sofreu impedimentos e interdições. E por quê?

Em nosso entendimento, tal pergunta é necessária pois como dito neste texto com outros argumentos, algumas Weltanschauung se impõem sobre outras. É o já citado problema da hegemonia versus contra hegemonia, pois onde há imposição também há resistência. Assim sendo, como tentamos apontar desde o início de nossa discussão ao longo deste texto, o folclore, as manifestações linguísticas regionais, as expressões populares, os neologismos e as contações de histórias são formas de mostrar que a linguagem e as interações não se efetivam por meio da prescrição de regras gramaticais, mas se constituem por meio das práticas sociais (culturais, históricas, ideológicas). Outrossim, o domínio multiletrado e 
multidimensional pode favorecer o diálogo entre culturas, entre visões de mundo e entre "mundos tão diversos e distintos". Isso evidencia a dimensão transcultural das questões folclóricas aqui problematizadas.

A complexidade do conceito de Tylor encontra solo fértil na complexidade do encontro com tantas culturas diferentes no século XXI, marcado essencialmente pela volatividade, pela velocidade e pela transitoriedade. A abertura ao diferente não é só um fenômeno contemporâneo, mas uma condição que evidencia nossa própria condição de sujeitos neste mundo eminentemente complexo. Um dos autores que confirma com grande veemência esta intuição é Edgar Morin:

\begin{abstract}
Acontece que o problema da complexidade não é o da completude, mas o da incompletude do conhecimento. [...] Por exemplo, se tentamos pensar no fato de que somos seres ao mesmo tempo físicos, biológicos, sociais, culturais, psíquicos e espirituais, é evidente que a complexidade é aquilo que tenta conceber a articulação, a identidade e a diferença de todos esses aspectos, enquanto o pensamento simplificante separa esses diferentes aspectos, ou unifica-os por uma redução mutilante. Portanto, nesse sentido, é evidente que a ambição da complexidade é prestar contas das articulações despedaçadas pelos cortes entre disciplinas, entre categorias cognitivas e entre tipos de conhecimento. De fato, a aspiração à complexidade tende para o conhecimento multidimensional. Ela não quer dar todas as informações sobre um fenômeno estudado, mas respeitar suas diversas dimensões: assim como acabei de dizer, não devemos esquecer que o homem é um ser biológico-sociocultural, e que os fenômenos sociais são, ao mesmo tempo, econômicos, culturais, psicológicos etc. Dito isto, ao aspirar a multidimensionalidade, o pensamento complexo comporta em seu interior um princípio de incompletude e de incerteza (MORIN, 2005, p. 176-177).
\end{abstract}

Com base nas ideias de Morin, conclui-se que o diálogo inter e transcultural é um elemento característico da complexidade, pois "conversar com a alteridade" significa compreender que nossas convicções, palavras, sentimentos e sensações, bem como, as "verdades do outro" estarão sempre assinaladas pela incompletude e pela falta constitutiva. Uma visão de mundo, nesse caso, só pode participar da interação com o outro se for considerada, de antemão, como incompleta e complexa. Ou, como diria Habermas (2012), a capacidade argumentativa e interacionista de todos os seres humanos só é possível quando superamos nossa Weltanschauung subjetiva rumo à uma visão de mundo intersubjetiva.

Assim sendo, todas as formas de expressão cultural (folclore, linguagem, interações, etc) devem ser consideradas como fundamentais em uma perspectiva transcultural. As heranças de um pensamento único sobre cultura devem ser ressignificadas ou reinterpretadas 
por um pensamento múltiplo que possa ampliar todas as visões de mundo possíveis. Não se trata, pois de abandonar os modos culturais herdados do passado; basta que sejamos capazes de reconsiderar os paradigmas do passado com as necessidades do presente que, em nosso entendimento, deve passar pela lente atenta da transculturalidade.

\section{Considerações finais}

O objetivo do artigo foi definir e estabelecer a inter-relação entre linguagem, cultura e Weltanschauung e constatar as contribuições do folclore na manutenção dos aspectos culturais locais, bem como propiciar aos leitores a ideia da importância dos conceitos para a preservação da identidade cultural dos povos, ao mesmo tempo em que ressalta a necessidade da abordagem transcultural na aquisição da consciência cultural de cada um.

Ao se conceber a ideia de que cultura e linguagem são fenômenos sociais indissociáveis, que se constroem mutuamente e dialogicamente, há que se considerar que os textos orais e escritos, entendidos como literatura, são contribuições da cultura de uma época que, mesmo temporalmente distante de nós, não é fechada em si mesma, como algo pronto e acabado, mas sim como uma unidade aberta, capaz de irradiar o passado e projetar o futuro. Em cada cultura há imensas possibilidades de construção de novos sentidos, pois admitem novas descobertas e até mesmo reconstruções de sentidos já estabelecidos, sejam as culturas contemporâneas ou constituídas em épocas diferentes.

Dessa forma, manter vivos os costumes de nossos antepassados, através das histórias contadas ou escritas é um meio de dialogar com a cultura de uma época, ao mesmo tempo que nos apropriamos da sua forma de ver o mundo e entendemos melhor o espaço do qual fazemos parte.

Então, ao se entender o folclore de um povo como parte essencial de sua cultura, entende-se também a relação dialógica entre diferentes maneiras de ver e entender o mundo, na medida em que esse possui instrumentos para revelar a cultura do outro, de forma plena e profunda; entende-se também que seu estudo é fundamental para a transculturalidade da própria cultura.

Assim sendo, na relação estabelecida entre linguagem, cultura e folclore, há que se considerar que, na dialogicidade da linguagem, o sentido só se revela profundo no contato com o outro, pois é o outro que nos permite perceber como sujeitos sociais, que habitam um 
espaço e incorporam a cultura desse espaço. Essa relação supera o fechamento e a unilateralidade dessa cultura, que na relação transcultural não se funde, nem se confunde, mas se enriquece mutuamente.

Ora, se é necessário que percebamos a cultura do outro para nos tornarmos conscientes da nossa própria; então, é na transculturalidade que encontraremos espaço para a percepção de nós mesmos enquanto sujeitos histórica e socialmente construídos, através da consciência da existência de outras manifestações culturais, e que essas são, na verdade, instrumentos para o desenvolvimento de nossa criticidade e capacidade de transformar àquilo que nos incomoda no nosso próprio território cultural.

\section{Referências}

BARROSO, Priscila Farfan; BONETE, Wilian Junior; QUEIROZ, Ronaldo Queiroz de Morais. Antropologia e Cultura. [revisão técnica: Guilherme Marin]. Porto Alegre: SAGAH, 2017.

BONVINI, Emilio. Textos orais e textura oral. In: QUEIROZ, Sônia. A tradição oral. Tradutoras Ana Elisa Ribeiro, Fernanda Mourão e Sônia Queiroz. 2. ed. FALE/UFMG. Belo Horizonte, 2016.

BRANDT, Ana Luisa; GUSTSACK, Felipe; FELDMANN, Juliana. Mediação literária: propostas de oralização. Reflexões sobre a contação de histórias: uma proposta para integrar oralidade, leitura e escrita. Caxias do Sul. v. 14, n. 2, maio/ago. 2009.

BRASIL. Presidência da República Casa Civil, Brasília, DF. DECRETO No 56.747, DE 17 DE AGOSTO DE 1965. Disponível em: http://www.planalto.gov.br/ccivil_03/decreto/19501969/D56747.htm. Acesso em 27 de abril de 2021.

BRASIL. Constituição (1988). Constituição da República Federativa do Brasil. Brasília, DF. Disponível em: http://www.planalto.gov.br/ccivil_03/constituicao/constituicao.htm. Acesso em 27 de abril. 2021.

CIRACI, Fabio. A filosofia como cosmovisão. Tradução de Leandro de Araújo Sardeiro. Revista Problemata - Revista Internacional de Filosofia (UFPB). V. 10. n. 5 (2019), p. 265270. (Doi: http://dx.doi.org/10.7443/problemata.v10i5.49923).

COMISSÃO NACIONAL DO FOLCLORE BRASILEIRO. Carta do folclore brasileiro. Salvador, BA, CNF, 1995. Disponível em: https://www.fundaj.gov.br/geral/folclore/carta.pdf. Acesso em 27 de abril de 2021.

GERALDI, João Wanderlei. Bakhtin Tudo ou Nada Diz aos Educadores: Os Educadores Podem Dizer Muito Com Bakhtin. In: FREITAS, Maria Teresa de Assunção (org). Educação, Arte e vida em Bakhtin. Autêntica. Belo Horizonte. 2013.

GOMES, Luiz Roberto. Educação e Consenso em Habermas. Campinas, São Paulo: Edt. Alínea, 2007. 
HABERMAS. Jürgen. Teoria do Agir Comunicativo 1: Racionalidade da Ação e Racionalização Social. Tradução de Paulo Astor Soethe. Revisão de tradução: Flávio Beno Siebeneichler. São Paulo, Editora WMF Martins Fontes, 2012.

LORENZETTI, Carmen; CAMPOS, Karin Cozen de. A Contação de Histórias como Gênero Oral Ensinável Mediado Pela Leitura na Obra Tristão e Isolda. Cadernos PDE. vol 1. Paraná.2013.

MEGALE, Nilza Botelho. Folclore Brasileiro. 5. ed. Petrópolis: Vozes, 2011.

MORIN, Edgar. Ciência com consciência. Tradução de Maria D. Alexandre e Maria Alice Sampaio Dória. 8a ed. - Rio de Janeiro: Bertrand Brasil, 2005.

OLIVEIRA, Aroldo Magno de. Memória, Percepção, Autoria e Divulgação. In:

NASCIMENTO, Luciana; ASSIS, Lúcia Maria de; OLIVEIRA, Aroldo Magno de (orgs). Linguagem e Ensino do Texto: Prática e Teoria. -Rio de Janeiro: Edgard Blücher Ltda. 2016.

PINHEIRO, Noslen Nascimento. A Expressividade dos Neologismos Sintagmáticos na prosa de Mário de Andrade. São Paulo. 2008.

RABAÇAL, Alfredo João. Influência indígenas no folclore brasileiro. Separata da Revista de Etnografia n. 14- Museu de Etnografia e História 19 p. Porto (Portugal). Disponível em: http://etnolinguistica.wdfiles.com/local--files/biblio\%3Arabacal-1967. Acesso em 01 de maio de 2021.

TYLOR, Edward. Primitive Culture. Ed. John Mursay \& Co. Londres, 1871.

ZANCHETTA, Heloísa Bacchi. Aspectos culturais como fios condutores de interações em Tandem na aprendizagem de português língua estrangeira: interculturalidade, estereótipos e identidade(s). Dissertação de Mestrado pelo Programa de Linguística e Língua Portuguesa da Faculdade de Ciências e Letras - (UNESP) Araraquara - SP. 2015.

Recebido em: julho 2021. Aprovado em: setembro/2021. 